\title{
Spectroscopic Studies on PVA-Chitosan Blend with Potassium Nitrate as Ionic Crosslinker for Biomedical Application
}

\author{
Firdos Jahan $^{1 *}$, R.D. Mathad ${ }^{2}$ \\ ${ }^{1}$ Department of Post Graduate Studies and Research in Physics, Gulbarga University, Kalaburgi, India \\ ${ }^{2}$ Department of Post Graduate Studies and Research in Physics, Gulbarga University, Kalaburgi, India
}

Available online at: www.isroset.org

Received: 05/Apr/2019, Accepted: 14/Apr/2019, Online: 30/Apr/2019

\begin{abstract}
The present research aimed to study the energy band gaps of Chitosan (CS) -Polyvinyl Alcohol (PVA) blend films crosslinked with Potassium nitrate $\left(\mathrm{KNO}_{3}\right)$. The morphology of the film surface and blending were investigated by Scanning Electron Microscopy (SEM). The UV-visible spectroscopic studies were done by Parking Elmer UV/Vis Spectrometer Lamda-35. The increase in the absorption intensity and decrease in the optical band gap may be due to a larger absorption increment associated with the charge transfer transition and a similarly Optical conductivity of samples increases due to the decrease in optical band gap and hence promises to be a good material for the biomedical and battery applications.
\end{abstract}

Keywords - Chitosan-Polyvinyl Alcohol blend, Potassium nitrate, absorption maxima, direct and indirect energy band gap

\section{INTRODUCTION}

Polymer blending is a method that is commonly used for providing desirable polymeric materials with the combined properties suitable for particular applications. Investigation of blends of chitosan with synthetic and naturally occurring macromolecules has attracted much attention in the recently years in various occasions [1-5]. Blending of chitosan with synthetic polymers is a convenient method for preparation of synthetic biodegradable polymers having versatile properties such as good water absorbance and enhanced mechanical properties while maintaining biodegradability[6] and chitosan [poly-b(1-4)-d-glucosamine], have recently been reevaluated and found to be useful resources and functional materials [7-8].However, their homopolymers are inadequate to meet the diversity of our demands for materials. Polymer blending is one of the most effective methods for providing new, desirable polymeric materials for practical applications. Chitosan membranes blended with poly(vinyl alcohol)(PVA) have already been reported to have good mechanical properties because of the specific intermolecular interactions between PVA and chitosan in the blends.

polymeric chains are interconnected by crosslinkers, leading to the formation of a 3D network. Crosslinkers are molecules of MW much smaller than the MW of the chains between two consecutive crosslinks. The properties of crosslinked hydrogels depend mainly on their crosslinking density, namely the ratio of moles of crosslinking agent to the moles of polymer repeating units. Moreover, a critical number of crosslinks per chain is required to allow the formation of a network, such as that of a hydrogel.
Depending on the nature of the crosslinker, the main interactions forming the network are covalent or ionic bonds. The structures and interactions forming the covalently and ionically crosslinked polymers will be presented, their principles of formation and properties will be considered and examples of medical or pharmaceutical applications will be given. Their potential biocompatibility will be discussed, although some examples will refer to systems that are still in development.

Ionic crosslinking is a simple and mild procedure. In contrast to covalent crosslinking, no auxiliary molecules such as catalysts are required [9], which is of great interest for medical or pharmaceutical applications. Indeed, ionic crosslinking can be ensured by the classical method of preparing a crosslinked network, namely by the addition of the crosslinker, either solubilised [10] or dispersed [11], to the chitosan solution. Chitosan can be crosslinked by simply dipping pieces of chitosan film into the crosslinker solution [12] or by adding the chitosan solution to the crosslinker solution $[13,14,15]$ through a syringe for example. These latter methods induce the formation of systems that are similar to gel particles.

The objective of this study was to develop chitosan based film by blending and crosslinking with polyvinyl alcohol and Potassium nitrate $\left(\mathrm{KNO}_{3}\right)$ in order to study the energy band gaps of chitosan biopolymer .This modified PVA-CS film may be a promising material in packaging applications, battery and biomedical applications. 


\section{MATERIALS AND MeTHODS}

Shrimp source Chitosan in a form of white flaks with a degree of deacetylation of $88.1 \%$ defined by UV method [25] was obtained from commercial source. Polyvinyl alcohol was purchased from Sigma Chemicals Co. (UK). Acetic acid (glacial 100\%, pro analysis) was purchased from Merck (Germany). Poatssium niktrate $\left(\mathrm{KNO}_{3}\right)(\mathrm{M}=101.1032 \mathrm{~g}$ $\mathrm{mol}^{-1}$ ) was purchased from Merck (Germany), Methanol AR $\left(\mathrm{CH}_{4} \mathrm{O}\right)(\mathrm{M}=32.04)$ was purchased from $\mathrm{S}$ D Fine chemical Mumbai. Ultra pure water (Elga-Prima Corp, UK) with a resistivity higher than $18 \mathrm{M} \Omega \mathrm{cm}^{-1}$ was used to prepare all solutions. All chemicals were used without further purification and freshly prepared solutions were always used in all experiments.

\section{1: Synthesis of CS/PVA blend and its crosslinked films:}

Chitosan was grounded and dried in an oven until a constant weight was observed. A $10 \mathrm{~g} \mathrm{~L}^{1}$ solution of Cs was prepared by dissolving $5 \mathrm{~g}$ of chitosan in $500 \mathrm{ml}$ of acetic acid $(0.1 \mathrm{M})$ followed by stirring and heating at $60^{\circ} \mathrm{C}$ for 14 to $16 \mathrm{~h}$. The solution was filtered before being used to remove the undissolved particles. The PVA powder was dissolved in preheated ultra pure water, followed by stirring at a temperature of $90^{\circ} \mathrm{C}$ for about 2 hours until clear solutions were obtained. To prepare the CS-PVA blend, $50 \mathrm{ml}$ of Cs and $50 \mathrm{ml}$ of PVA solutions were mixed and stirred at $90^{\circ} \mathrm{C}$ for $30 \mathrm{~min}$ to obtain homogeneous blended solutions. The $\mathrm{pH}$ of the solution was maintained at levels higher than $\mathrm{pH} \sim 6$ to avoid Cs precipitation.

The obtained homogeneous of CS-PVA (50-50) solution was cast into a polystyrene Petri dish, after removing all trapped air bubbles. The cast solution was then allowed to dry in a vacuum oven at $60^{\circ} \mathrm{C}$ to form a uniform and homogenous film with a thickness of about $14 \pm 2 \mu \mathrm{m}$. The film thicknesses were obtained at various positions of the samples using a digital thickness gauge and the reported data is the average of 3 readings.

The blended films were ionically crosslinked using the method described by Huang et al. [26]. The dried of CSPVA (50-50) films were immersed in a different weight percentages of Poatssium nitrate in aqueous methanol solution, as shown in table 1 . The crosslinking reaction was allowed to continue for 30-40 min at room temperature under continuous stirring. The crosslinked films were removed, and then placed under vacuum for drying.

Table 1: Polymer blend samples with $\mathrm{KNO}_{3}$ as Crosslinker.

\begin{tabular}{|c|c|c|}
\hline SI.No & $\begin{array}{c}\text { Films designation } \\
\text { PVA/CHITOSAN(50/50) blend films }\end{array}$ & $\begin{array}{c}\text { Poatssium Nitrate in } \\
\text { Methanol (wt\%) as } \\
\text { crosslinker }\end{array}$ \\
\hline 01 & PVA/CS (50/50) blend (PC blend) & 0 \\
\hline 02 & PVA/CS (50/50) blend (CPKN-1) & 0.1 \\
\hline 03 & PVA/CS (50/50)blend (CPKN-2) & 0.2 \\
\hline 04 & $\mathrm{PVA} / \mathrm{CS}(50 / 50)$ blend (CPKN-3) & 0.3 \\
\hline 05 & $\mathrm{PVA} / \mathrm{CS}(50 / 50)$ blend (CPKN-4) & 0.4 \\
\hline 06 & $\mathrm{PVA} / \mathrm{CS}(50 / 50)$ blend (CPKN-5) & 0.5 \\
\hline
\end{tabular}

\section{RESULTS AND DISCUSSION}

\section{1: MORPHOLOGICAL STUDIES OF CS-PVA BLEND AND ITS CROSSLINKED FILMS:}

Figure 1 shows the SEM images of the surfaces of PVA-CS blended film and its corresponding crosslinked films as ionic croslinker. In fig 1 (a) shows smooth and homogenous surface with no straps or lumps unlike that of (b) and (c) where some straps are seen because of the ionic salt, which is deposited on the surface of the blended film $[18,19]$. This indicates the uniform distribution of CS and PVA molecules throughout the films and is caused by the interaction of hydrogen bonds between the functional groups of the blended components (-OH and $-\mathrm{NH}_{2}$ groups in chitosan and $-\mathrm{OH}$ groups in PVA), further, the images (b) and (c) (CPKN-1,CPKN-2) shows that the crosslinking is achieved by completely modifying the surface morphology of crosslinked of PVA-CS (50-50) blend.

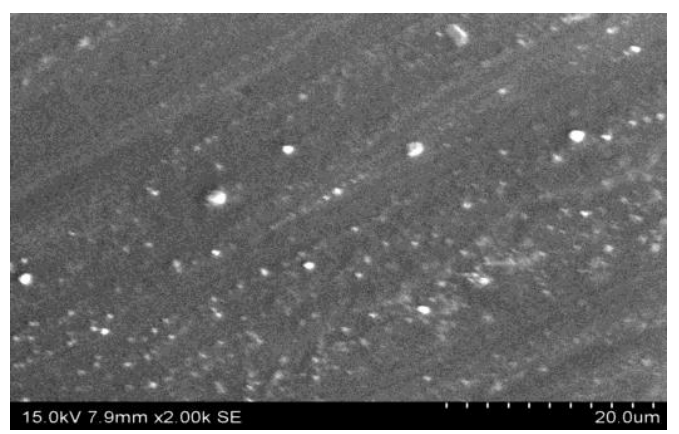

FIGURE 1: (a) SEM image of PVA/CS (50/50) blend film

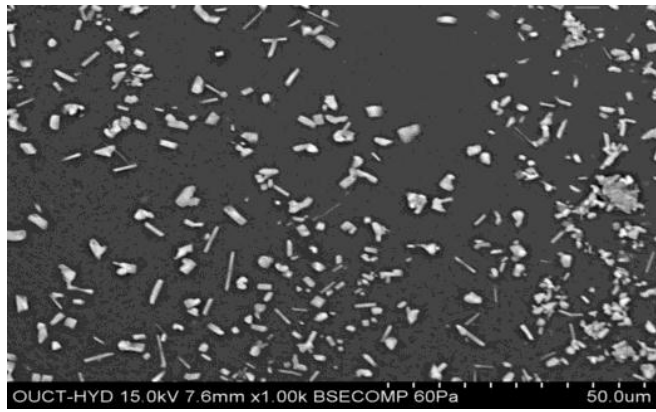

(b): SEM image of CPKN-1 film

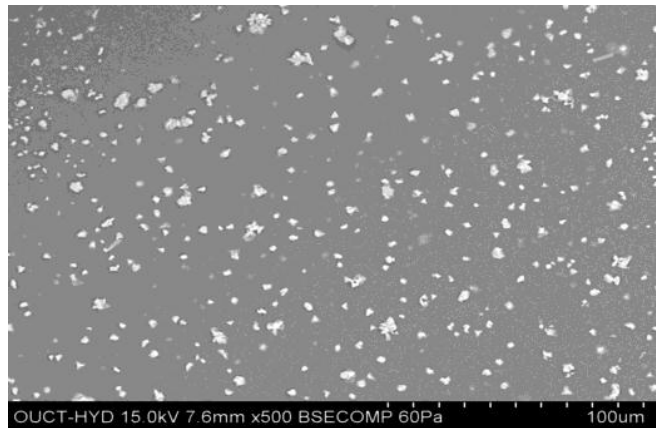

(c): SEM image of CPKN-2 film 


\section{OPTICAL PROPERTIES:}

Figure 3 of (a) shows optical absorption spectra recorded for blend PVA-CS polymer in the region 200-900 nm. The optical band gap of films can be calculated by using the intercept method and the following formula.

$$
(\alpha h v)^{n}=A(h v-E g)
$$

Where $\alpha$ is the absorption coefficient near the absorption edge, $\mathrm{A}$ is a constant and $n$ characterizes the transition process. Here $n=2$ and $1 / 2$ stands for the direct band gap and indirect band gap, respectively. A shift in absorption towards the higher wavelengths has been observed, these shifts indicate the formation of inter/intra molecular hydrogen bonding mainly between nitrate ions with that of these adjacent $\mathrm{OH}$ groups, The decrease in transmission for crosslinked PVA-CS films reflect the variation in the optical band gap which arises due to the change in polymer structure. We have made an attempt of evaluating optical band gap of these crosslinked polymer films using Tauc plot. Figure 3 of (b) and (c) shows the photon energy $(h v)$ is plotted against $(\alpha h v)^{2}$ and $(\alpha h v)^{1 / 2}$. It gives a straight line fit, which implies that the samples undergo direct and indirect transition. Then the band gap has been extracted by extrapolating the straight portion of the graph on $h v$ axis at $\alpha$ $=0$. The calculated values of the optical band gap for all prepared polymer electrolyte films are given in table 2 .

Table 2. The values of the optical band gap decreasing with increasing concentration of KNO3.

\begin{tabular}{|c|c|c|c|}
\hline SL.NO. & FILM DESIGNATION & $\begin{array}{c}\text { DIRECT } \\
\mathbf{E}_{\mathbf{g}}(\mathbf{e V})\end{array}$ & $\begin{array}{c}\text { INDIRECT } \\
\mathbf{E}_{\mathbf{g}}(\mathbf{e V})\end{array}$ \\
\hline 01. & PVA-CS(50-50)blend & 2.80 & 2.6 \\
\hline 02. & CPKN-1 & 2.65 & 2.4 \\
\hline 03. & CPKN-2 & 2.55 & 2.2 \\
\hline 04. & CPKN-3 & 2.45 & 2.1 \\
\hline 05. & CPKN-4 & 2.30 & 1.8 \\
\hline 06. & CPKN-5 & 2.20 & 1.5 \\
\hline
\end{tabular}

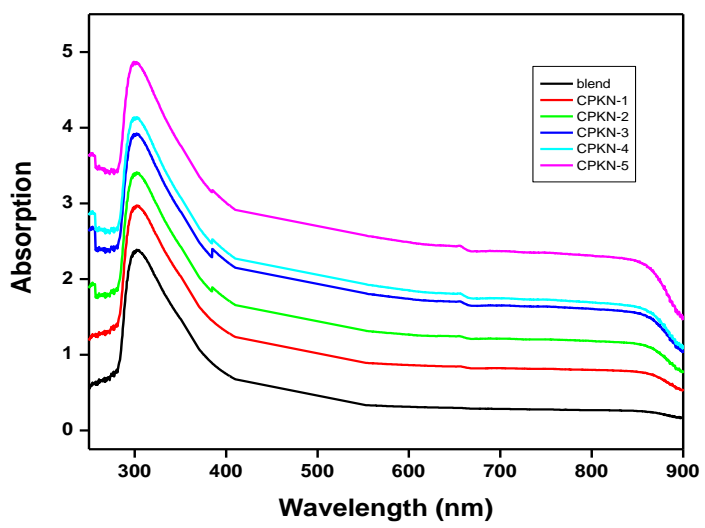

Fig 5.4.3(a): Optical absorption spectra for various blend and its crosslinked films.

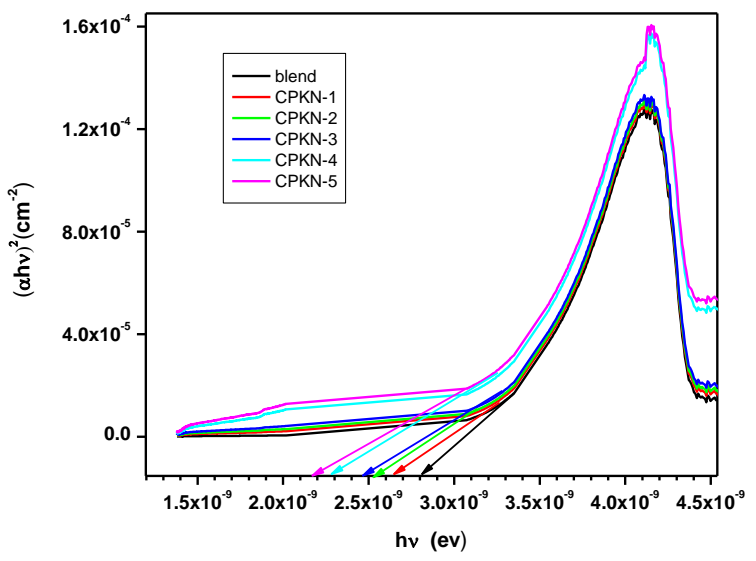

Fig 5.4.3(b): : Plot of $(\alpha h v)^{2} v / s(h v)$ for various blend and its crosslinked films.

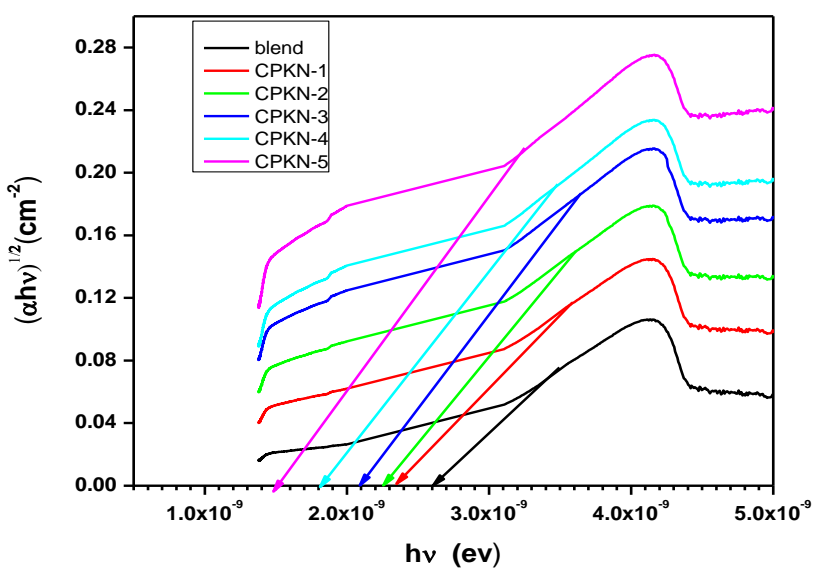

Fig 4.4.3(c): Plot of $(\alpha h v)^{1 / 2} v / s(h v)$ for various blend and its crosslinked films.

\section{CONCLUSION}

PVA-CS blend and its crosslinked films with ionic crosslinker $\mathrm{KNO}_{3}$ is prepared. From SEM it is clear that PVA-CS blending along with its crosslinker is acheived successfully. The UV-Vis spectra show the existence of optical energy band gap in these crosslinked films and the values of optical band gaps are decreasing with increasing concentration of KNO3. The decrease in transmission for crosslinked PVA-CS films reflects the variation in the optical band gap which arises due to the change in polymer structure. This modified chitosan film may be a promising material in packaging, biomedical and battery applications .

\section{Acknowledgements}

The author is thankful to UGC-BSR, NEW DELHI, for providing Fellowship, and also thankful to Prof. MVN 
Ambika Prasad for providing UV-Visible spectroscopy in USIC department, Gukbarga University, Kalaburagi, Karnataka, India.

\section{REFERENCES}

[1] Mucha M, React Funct Polym., 1998, 38, 19.

[2] Srinivasa P C, Ramesh M N, Kumar K R and Tharanathan R N, Carbohydr Polym.,2003, 53(4), 431438.

[3] Shanmugasundaram N, Ravichandran P, Neelakanta P R, Nalini R, Subrata $P$ andRao K P, Biomaterials, 2001,22,1943.

[4] Chen X G, Wang Z, Liu W S and Park H J, Biomaterials, 2002, 23(23), 4609-4614.

[5] Sionkowska A, Wisniewski M, Skopinska J, Kennedy C J and Wess T J,Biomaterials, 2004, 25(5), 795-801.

[6] Engelberg I and Kohn J, Biomaterials, 1991, 12, 292304.

[7] Li Q, Dunn ET, Grandmaison EW, Goodman MFA. J Bioact CompatPolym 1992;7:370.

[8] Chandy T, Sharma CP. Biomat Art Cells Art Org1990;18:1.

[9] F.L. Mi, S.S. Shyu, T.B. Wong, S.F. Jang, S.T. Lee, K.T.Lu,Chitosan polyelectrolyte complexation for the preparation of gel beads and controlled release of anticancer drug. II. Effect of pHdependent ionic crosslinking or interpolymer complex using tripolyphosphate or polyphosphate as reagent, J. Appl. Polym. Sci.74 (1999) 1093-110.

[10] X.Z. Shu, K.J. Zhu, W. Song, Novel pH-sensitive citrate cross-linkedchitosan film for drug controlled release, Int. J. Pharm. 212 (2001)19-28.

[11] F.L. Mi, C.T. Chen, Y.C. Tseng, C.Y. Kuan, S.S. Shyu, Iron(III)-carboxymethylchitin microsphere for the pHsensitive release of 6-mercaptopurine, J. ControlledRelease 44 (1997) 19-32.

[12] E. Ruel-Gariepy, A. Chenite, C. Chaput, S. Guirguis, J.C. Leroux,Characterization of thermosensitive chitosan gels for the sustaineddelivery of drugs, Int. J. Pharm. 203(2000) 89-98.

[13] K.I. Draget, K.M. Varum, E. Moen, H. Gynnild, O.Smidsrod, Chitosan cross-linked with Mo(VI) polyoxyanions: a new gelling system, Biomaterials 13(1992) 635-638.

[14] X.Z. Shu, K.J. Zhu, Controlled drug release properties of ionically cross-linked chitosan beads: the influence of anion structure, Int. J. Pharm. 233 (2002) 217-225.

[15] X. Shu, K.J. Zhu, A. novel, approach to preparetripolyphosphate/chitosan complex beads for controlledrelease drug delivery, Int.J. Pharm. 201 (2000) 51-58.

[16] M K . Cheung, Wan K P Y and Yu P H, J Appl Polym Sci., 2002, 86,
[17] Huang Y, Yu H and Xiao C, Carbohydr Polym., 2007, 69, 774.

[18] F. Peng , Pan F, sun, H, Lu L and jiang Z, j Membr Sci., 2007, 300, 13-19.

[19] S.Raghunadh Acharyulu, T. Gomathi and P. N. Sudha,2013. 